\title{
BMJ open Public health concerns for anti-obesity medicines imported for personal use through the internet: a cross-sectional study
}

\author{
Mohiuddin Hussain Khan, ${ }^{1}$ Tsuyoshi Tanimoto, ${ }^{2}$ Yoko Nakanishi, ${ }^{1,3}$ \\ Naoko Yoshida, ${ }^{1}$ Hirohito Tsuboi, ${ }^{1}$ Kazuko Kimura ${ }^{1}$
}

To cite: Khan MH, Tanimoto T, Nakanishi Y, et al. Public health concerns for anti-obesity medicines imported for personal use through the internet: a cross-sectional study. BMJ Open 2012;2:e000854. doi:10.1136/ bmjopen-2012-000854

- Prepublication history for this paper is available online. To view this file please visit the journal online (http://dx. doi.org/10.1136/ bmjopen-2012-000854).

Received 11 January 2012 Accepted 5 April 2012

This final article is available for use under the terms of the Creative Commons Attribution Non-Commercial 2.0 Licence; see http://bmjopen.bmj.com

${ }^{1}$ Drug Management and Policy, Kanazawa University, Kanazawa City, Ishikawa, Japan

${ }^{2}$ Department of Analytical Sciences, Faculty of Pharmaceutical Sciences, Doshisha Women's College, Kyoto, Japan

${ }^{3}$ Food Safety Department, Health Center of Kanazawa City, Kanazawa City, Ishikawa, Japan

Correspondence to Dr Mohiuddin Hussain Khan; mohiuddin_khn@yahoo.com

\section{ABSTRACT}

Objective: To explore the circulation of anti-obesity medicines via the internet and their quality.

Design: Cross-sectional study.

Setting: Internet pharmacies and pharmaceutical suppliers accessible from Japan.

Participants: Anti-obesity medicines were purchased using relevant keywords on Japanese Google search engine. Blogs and advertisement-only sites were excluded.

Primary and secondary outcome measures: The authenticity of the samples was investigated in collaboration with the manufacturers of the samples and medicine regulatory authorities. Quality of the samples was assessed by pharmacopoeial analyses using high-performance liquid chromatography.

Results: 82 samples were purchased from 36 internet sites. Approximately half of the sites did not mention a physical address, and $45 \%$ of the samples did not contain a package insert. A variety of custom declarations were made for the shipments of the samples: personal health items, supplement, medicines, general merchandise, tea and others. Among 82 samples, 52 samples were analysed to check their pharmacopoeial quality. Authenticity responses were received from only five of 20 manufacturing companies. According to the pharmacopoeial analyses and authenticity investigation, three of the samples were identified as counterfeits and did not contain any active ingredients. Two of these samples were confirmed as counterfeits by the manufacturer of the authentic products. The manufacturer of the other sample did not respond to our request for an authenticity check even after several communication attempts. These counterfeit cases have been reported at the rapid alert system of Western Pacific Region of the WHO.

Conclusions: Many counterfeit and unapproved antiobesity medicines may be easily bypassing regulatory checks during shipping and are widely circulated through the internet. Regulatory authorities should take measures to prevent these medicines from entering countries to safeguard their citizens.

\section{ARTICLE SUMMARY}

Article focus

- Quality of online anti-obesity medicines.

- Circulation of unapproved anti-obesity medicines via the internet.

\section{Key messages}

- Counterfeit and substandard anti-obesity medicines, orlistat are identified.

- False and vague custom declarations were made by some of the shipping companies to bypass regulatory checks of unapproved online medicines.

Strengths and limitations of this study

- Small sample size and low authenticity response rate are limitations of this study.

- However, the study provides valuable information for regulatory authorities on how unapproved and counterfeit medicines are being circulated through the internet.

- Concerted efforts of authentic manufacturers and medicine regulatory authorities are a must to combat counterfeits and ensure access of quality medicines to online consumers.

\section{INTRODUCTION}

Over the past decade, the internet has become an integral part of life for a variety of uses. Approximately $60 \%$ of internet users in some developed countries, such as Japan and the USA, use the internet for their healthrelated activities. ${ }^{1-4}$ In fact, when internet users were asked about specific searches related to health, such as diet and fitness information or health insurance materials, $80 \%$ of the users among adult Americans in a 2002 survey said that they had performed these types of searches. ${ }^{1}$ According to a survey taken in Japan, a majority $(86.3 \%)$ of the medicines imported for personal use were purchased through the internet. ${ }^{5}$ 
However, according to the WHO, more than $50 \%$ of the medicines from internet sites, which often conceal their physical address, may be counterfeit or of substandard quality. ${ }^{6}$ The WHO defines counterfeit medicines as the ones that are deliberately and fraudulently mislabelled with respect to identity and/or source. ${ }^{7-9}$ On the other hand, substandard medicines are legitimate ones that do not meet the quality specifications claimed by their manufacturers. ${ }^{10}$

A number of reports documented the severity of drug counterfeiting during the past 2 decades. The WHO found that $20 \%-90 \%$ of drugs were counterfeited in some African countries. ${ }^{11}{ }^{12}$ In Tanzania, $12.2 \%$ of antimalarials were identified as substandard in $2005 .{ }^{13}$ In $2009,37 \%$ of the samples did not meet standards in Nigeria. ${ }^{14}$ Similar evidences were also reported in Asia. ${ }^{15-17}$ The unprecedented growth of the internet accompanied with globalisation of e-commerce might have worsened the situation further. ${ }^{18-20}$

Obesity is becoming a major public health epidemic in this century and is associated with an increased risk for a number of health problems, such as hypertension, dyslipidaemia, type 2 diabetes and cardiovascular diseases. ${ }^{21}$ The prevalence of obesity and its associated conditions are increasingly affecting developed and developing countries over the past few decades. ${ }^{22}$ Studies suggest that primarily adolescent and adult men are overweight or obese in Japan. ${ }^{23}$ Recommended strategies for managing weight and obesity include lifestyle changes with appropriate dietary management and exercise. However, individuals with an isolated body mass index of $\geq 30$ or $>27 \mathrm{~kg} / \mathrm{m}^{2}$ with comorbidities, such as type 2 diabetes, cardiovascular diseases and obstructive sleep apnoea, should receive pharmacotherapy as well. ${ }^{24}$ Among the available anti-obesity medicines, phentermine, diethylpropion and orlistat are approved by the US Food and Drug Administration, but sibutramine has been withdrawn from the market. ${ }^{25}{ }^{26}$ Of these antiobesity medicines, only mazindol has been approved for use in Japan. ${ }^{27}$ However, several of these anti-obesity medicines are among those that are frequently imported into Japan for personal use. ${ }^{28}$ Safety profile, risk versus benefit, cost-effectiveness of investment deter manufacturers and marketers to get interested in approving antiobesity medicines for Japanese market. ${ }^{29}$

The online purchase of medicine through the internet is a growing and convenient practice for many consumers. This practice has also become one of the most popular, easiest and safest routes for counterfeit medicine traders. ${ }^{6}{ }^{30-32}$ The availability of counterfeit erectile dysfunction (ED) medicines was reported in Japan by a limited number of case investigations. ${ }^{33}{ }^{34}$ In addition, a joint investigation done by four pharmaceutical industries in Japan reported that approximately $60 \%$ of $\mathrm{ED}$ medicines available in the internet are counterfeited. ${ }^{34}$ However, the quality of anti-obesity and diet medicines available through the internet was still unknown. Since, all types of therapeutic classes of medicines are counterfeited from essential medicines to lifestyle drugs, an investigation was conducted to survey the quality of anti-obesity medicines that were purchased through online medicine sites. This investigation also provided an understanding of the process by which unapproved medicines are being imported for and used by consumers in Japan.

\section{METHODS}

\section{Study design}

Quality of online anti-obesity medicines was assessed using an online cross-sectional study during August 2009 .

\section{Selection of internet sites and sample collection}

Internet sites were selected in five steps to purchase anitobesity medicines. In the first step, the Japanese keywords personal import agent (個人輸入代行), diet (ダイエット) and obesity (肥満) were used on the Japanese Google search engine (http://www.google.co. jp). From a list of more than 140000 results, first 500 were further screened out to find online pharmacies or suppliers or brokers that offer anti-obesity medicines, provided that they did not mention their physical address in their websites. Websites with physical address and/or blogs and advertise-only sites were excluded in this step. In the second through fourth steps, searches were made on websites that advertise and sell counterfeit Cialis (シアリス), Levitra (レビトラ) and Viagra (バイア グラ). From our experiences on previous online medicine studies, we presumed that the websites offer counterfeit ED drugs and may also offer counterfeits of other varieties of medicines. ${ }^{5} 35$ As such, in the second step, the Japanese keywords personal import agent (“個人輸入 代行') and Cialis ('シアリス’), '50 mg' and ' $100 \mathrm{mg}$ ', were used, and first 100 results were further screened out from a list of more than 35000 . In the third step, the keywords personal import agent ('個人輸入代行') and Levitra ('レビトラ'), ‘50 mg' and ' $100 \mathrm{mg}$ ', were used, and again, first 100 results were screened out from a list of around 60000 . The physical characteristics (eg, colour of genuine and counterfeits, strength, packaging) of original and counterfeit Cialis and Levitra were identified earlier by the Ministry of Health, Japan. ${ }^{33}$ In the fourth step, samples were purchased from nine internet sites where counterfeit Viagra (バイアグラ) was offered in the past. The information on these sites was provided by Pfizer. Finally, based on the information available from our previous research, we searched home pages of 10 domestic brokers, and four of them were selected for sampling.

After the exclusion of blogs and advertisement-only sites, 36 sites were chosen for the purchase of anti-obesity medicines. A list of overweight/anti-obesity medicines was sought on each of the selected sites. Available medicines in the lists were numbered consecutively according to their vertical or horizontal placement on the web pages, excluding foods and drinks items. We 
purchased one anti-obesity medicine that was listed first in one of the selected sites. In the subsequent selected websites, we purchased another brand or product of antiobesity medicines, which was listed first.

Information on the site's name, URL, compliance with Japanese rules of 'Act on Specified Commercial Transaction' (ASCT), email address, the name of the product and other information such as the dosage, efficacy and side effects, recommendation on consultation with doctors or pharmacists or opportunities for consultation were recorded while examining the sites from which at least one product was purchased. ASCT is the policy guidelines of all kinds of business transaction to protect interests of the consumers in Japan. These guidelines cover door-to-door sales, mail order sales, talemarketing, and so on. According to the ASCT, all e-commerce sites in Japan should mention their name, address(es), telephone numbers, prices of commodities, shipment procedure(s), and so on. ${ }^{36}$

\section{Observational analysis}

All the samples were given distinct codes when the shipments were received. The name of the product, dosage form, content information from the printed label, the manufacturers' name and address, the country of origin, the manufacture and expiration dates, lot, registration and licence numbers, presence of package insert and their languages, Japanese information/notes, information from the shipping company, the sending country, the date of shipment and arrival, and customs declaration notations were recorded for each of the samples.

\section{Chemical analysis}

Pharmacopoeial procedures for the analysis of the samples (ie, orlistat, sibutramine, rimonabant, benfluorex and lovastatin) were established and performed using high-performance liquid chromatography (HPLC), which are described briefly below. However, analytical methods and results of rhei rhubarb and herbal products (ie, Pachyma hoelen, Ophiopogonis tuber and dai dai hua) were excluded since they will be reported elsewhere.

\section{Preparation of the sample solutions}

Randomly selected capsules of orlistat and sibutramine samples were weighed accurately. After each capsule was weighed, the contents were removed, and the empty capsule shells were subsequently weighed. The difference between the weight of the whole capsule and the capsule shell was assumed to be the weight of the contents. To prepare sample solutions of lovastatin, benfluorex and rimonabant tablets, randomly chosen tablets were weighed accurately and subsequently crushed separately into powder. Approximately $80 \mathrm{ml}$ of methanol was added to the capsule's contents or tablet powder, and the mixture was sonicated for $30 \mathrm{~min}$. After sonication, methanol was then added to a volume of
$100 \mathrm{ml}$. The resulting solutions were filtered through a membrane filter (pore size: $0.45 \mu \mathrm{m}$ ) and used as the sample solutions.

\section{Preparation of standard solutions}

Three consecutive strengths of standard solutions were prepared by dissolving $0.375,0.75$ and $1.50 \mathrm{mg}$ of orlistat; $0.050,0.100$ and $0.200 \mathrm{mg}$ of sibutramine; 0.100 , 0.200 and $0.500 \mathrm{mg}$ of lovastatin; $0.100,1.50$ and $2.00 \mathrm{mg}$ of benfluorex; $0.100,0.200$ and $0.500 \mathrm{mg}$ of rimonabant in $1 \mathrm{ml}$ of methanol for each solution.

\section{Assay condition}

Ten microlitres of each sample solution and standard solution was placed in phials and assayed using a photodiode array of $225 \mathrm{~nm}$ wavelength $(200-400 \mathrm{~nm}$ range for spectra) with a stainless steel column with a $4.6 \mathrm{~mm}$ internal diameter and $15 \mathrm{~cm}$ length packed with octadecylsilanized silica gel for liquid chromatography $(5 \mu \mathrm{m}$ particle diameter) used with Mightysil RP-18 GP 150-4.6. The column temperature was maintained at $45^{\circ} \mathrm{C}$. A mixture of methanol and phosphate buffer, $\mathrm{pH} 7.0$ (17:3), was used as the mobile phase at a flow rate of $1.2 \mathrm{ml} / \mathrm{min}$.

\section{Authenticity investigation}

A catalogue and a questionnaire for all the samples were created that included the information from the printed labels of the product packages. The printed information was also checked against the information on the manufacturers' websites. The questionnaires were sent to the appropriate manufacturers with a portion of the samples for verification of their authenticity. The regulatory authorities for medicine in the country of origin were also contacted to verify the legitimacy of the products and their approval for marketing. After considering the WHO definition of counterfeit medicines, the gathered information was analysed to determine the authenticity of the individual samples and their manufacturers. ${ }^{7} 37$

\section{Statistical analysis}

Because of the small size of the sample, descriptive statistical analysis was performed using Microsoft Excel.

\section{RESULTS}

In the first step of the internet search, 15 sites were selected that did not show a physical address. In the second through fourth steps, six, two and nine of the websites were selected that concurrently advertised counterfeit Cialis, Levitra and Viagra, respectively. Two of the sites with fake Cialis and Viagra also did not show a physical address. Four of the websites were hosted by domestic shipping companies selected in the fifth step. A total of 82 samples from 31 varieties of anti-obesity products were purchased from 36 internet sites (table 1). On average, these sites offered 62 kinds of products (including diet foods and drinks). Some of these products were shipped in divided shipments and treated as 
Table 1 Active ingredient

\begin{tabular}{llcl}
\hline Active ingredient & Approval status in Japan & $\mathbf{n ~ ( \% )}$ & Classification \\
\hline Sibutramine hydrochloride & Not approved & $42(51.2)$ & Prescription medicine \\
Orlistat & Not approved & $15(18.3)$ & $\begin{array}{l}\text { Prescription medicine: } 10 \\
\text { Over the counter: } 5^{*}\end{array}$ \\
Rimonabant & Not approved & $2(2.4)$ & Prescription medicine \\
Benfluorex & Not approved & $2(2.4)$ & Prescription medicine \\
Lovastatin† & Not approved & $2(2.4)$ & Prescription medicine \\
Pachyma hoelen (茯苓) & Approved & $14(17.1)$ & Over the counter \\
Ophiopogonis tuber (麦阴冬) & Approved & $3(3.6)$ & Over the counter \\
Rhei rhubarb (大黄)† & Approved & $1(1.2)$ & Over the counter \\
Dai dai hua (代花) & Approved & $1(1.2)$ & Over the counter \\
Total & & $82(100.0)$ & \\
\hline *Alli (orlistat $60 \mathrm{mg})$. & &
\end{tabular}

distinct samples. However, only one of such identical samples was analysed for pharmacopoeial quality.

\section{Information available on the websites}

Different levels of compliance with ASCT were observed throughout all (36) the websites. ${ }^{36}$ For instance, all $(100 \%)$ of them mentioned the selling price, shipping charges for the goods and methods of payment. However, only 21 (58.3\%) of them provided telephone numbers, and only $17(47.2 \%)$ of them mentioned a physical address.

Information for email addresses and shipment procedures were presented on all the selected sites. However, only $21(58.3 \%)$ of them encouraged consumers to consult with a physician or pharmacist. Consultation services were available at two $(5.5 \%)$ of the sites. Dosage and administration, effects and efficacy, and side effects related to the products were explained in $18(50 \%), 23$ $(63.8 \%)$ and $17(47.2 \%)$ of the sites, respectively, despite the prohibition on advertisements for unapproved medicines.

\section{Information provided with the samples}

On examination of the printed materials, the languages of the package inserts were found to be in English for 14 $(17.1 \%)$ of the samples, Chinese for 13 (15.9\%), both Chinese and Korean for 10 (12.2\%), both English and Chinese for four $(4.9 \%)$, Turkish for two (2.4\%), both English and Thai for one (1.2\%), and English, Chinese and Russian for one $(1.2 \%)$ of the samples. However, $37(45.1 \%)$ of the samples did not have any package inserts.

\section{Shipment of the samples}

Samples were sent by 29 different shipping companies. The majority (13 companies) shipped from China, and the second largest group was from India (four companies). Others were shipped from the USA (three), Japan (two), Thailand (two), Switzerland (one), Hong Kong (one), Cambodia (one), the Fiji Islands (one) and Puerto Rico (one). The customs declaration was 'health product/personal health items' for 20 (24.4\%) of the samples, 'supplement' for $13(15.9 \%)$ of the samples, 'medicine' for $10(12.2 \%)$ of the samples and the actual name of the product in two $(2.4 \%)$ cases. However, 12 $(14.7 \%)$ of the samples were shipped with a declaration of general merchandise and/or tea, $11(13.4 \%)$ of them declared 'other' and $14(17.1 \%)$ of them did not mention anything as the declaration. Interestingly, one representative from an importing agent of a diet medicine clinic (Sabairato Yanhee and MD Clinic, http:// www.gop23.com/, accessed 27 October 2011) enquired over the telephone regarding the purpose for our purchase of the medicine and asked if we had any relationship with the Ministry of Health and Labour Welfare, Japan; they did not sell their products to us.

\section{Sample characteristics}

Of the 82 samples, $42(51.2 \%)$ were advertised on the websites as containing sibutramine hydrochloride and 15 $(18.3 \%)$ were advertised as orlistat. Rimonabant, benfluorex and lovastatin were advertised to be in two $(2.4 \%)$ of the samples. Rhei rhubarb was said to be in one, and the remaining $18(21.9 \%)$ samples were advertised to be herbal products (table 1). All these products were advertised by their brand names. Of the 64 synthetic products, 58 samples from 19 different products were prescription medicines; however, none of which requested a prescription for the purchase. Five brands of orlistat were over-the-counter medicines, and one sample, dai dai hua, was marketed as a natural supplement. Interestingly, dai dai hua was advertised as sibutramine by its agent, and the sample actually contained sibutramine as shown by chemical analysis. According to purported country of marketing authorisation holder, 25 sibutramine products originated from India (dispatched from India, Hong Kong and Fiji Islands), seven from China (dispatched from China), seven from Germany (dispatched from Hong Kong and Cambodia) and three from Hong Kong (dispatched from Cambodia). Among 15 orlistat products, seven originated from India (dispatched from India and Japan), five from the UK (dispatched from Switzerland, the USA and Japan), two from Switzerland (dispatched 
from Puerto Rico) and one from Thailand (dispatched from Thailand). Two rimonabant, two benfluorex and one lovastatin samples originated from India (dispatched from Thailand and Japan), France (dispatched from Hong Kong) and the USA (dispatched from the USA), respectively. All herbal products (including dai dai hua) originated from China, except two (ie, Pachyma hoelen), which are from the USA, however, dispatched from China.

\section{Quality analysis}

Of total, 52 samples (ie, sibutramine: 21, orlistat: 13, rimonabant: 2, benfluorex: 2, lovastatin: 1 and herbal products: 13) were analysed by HPLC to measure quantity of active ingredients in the samples. Thirty samples (received in divided shipments and identical to an analysed sample from a same source, respectively) were excluded because of the insufficient materials. Quantitative analysis by HPLC showed that all (21) the samples of sibutramine were in the acceptable range $(90 \%-110 \%)$, except one (mean content percentage of $60.2 \pm 7.6)$. No active ingredient was detected in three of the 13 samples of orlistat that we tested (figure 1). These three samples were identified to be counterfeit. Of these three counterfeit samples, two were found to be Xenical after analysis by the researchers and the manufacturer of the genuine products. No active ingredient was detected in the last sample, only starch (figure 1). The other counterfeit sample contained unknown excipients. None of the samples of lovastatin, benfluorex or rimonabant failed the HPLC analysis.

\section{Authenticity investigation}

Responses to our requests for authentication were received from only five of the 20 manufacturing companies of the genuine samples. According to the responses that we received, all the responding manufacturers were Good Manufacturing Practice (GMP) compliant. Of the 12 reported samples, two of the orlistat samples (Xenical) from the same manufacturer were confirmed to be counterfeit (table 2).

The counterfeit samples were purchased at http:// www.kenkoclinic.com and sent to us from Puerto Rico. They bore the same manufacture and expiration dates (MFD: 02-2011 and EXP: 02-2011, figure 2) on their blisters, which had not yet occurred at the time of our investigation. The printed information on the blisters of the counterfeits was a different colour with a similar but slightly different logo (figure 3).

Telephone communications were made to the manufacturer of Zenigal (orlistat $120 \mathrm{mg}$ ) in India, which did not contain any of the active ingredients that had been claimed on the product labels. However, the manufacturer did not respond after several communication attempts. This counterfeit Zenigal sample was sent to us from Japan. We reported that these three cases of counterfeit medicines at the rapid alert system of the Western Pacific Region of the WHO.

Responses were received from the medical regulatory authorities of three countries (Germany, Switzerland and the USA) for five of the manufacturers. Their responses stated that only orlistat has approval to be manufactured in Switzerland. Approval for the manufacture of

\section{B}
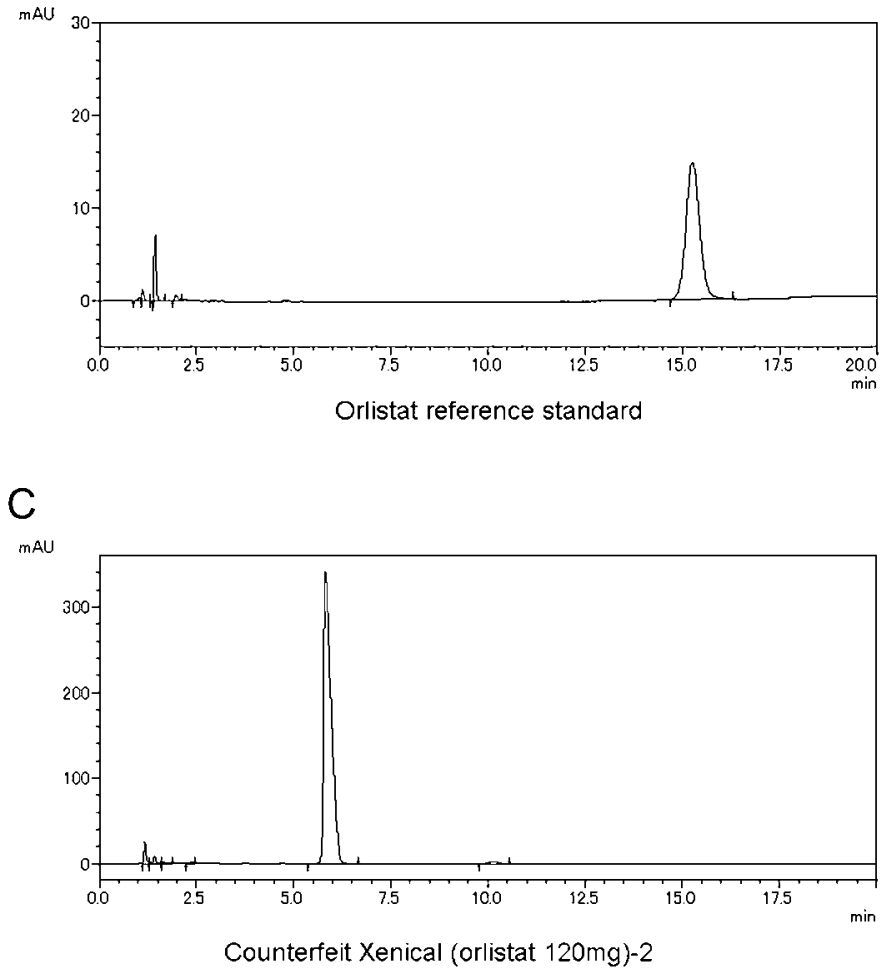

Figure 1 Chromatograms (A-D) of the reference standard of orlistat and counterfeit samples. 
Table 2 Results of authenticity investigation

\begin{tabular}{lllll}
\hline Active ingredient & $\begin{array}{l}\text { Labelled country of } \\
\text { marketing authorisation holder }\end{array}$ & Genuine sample & Counterfeit sample & $\begin{array}{l}\text { Manufacturing } \\
\text { licence }\end{array}$ \\
\hline Orlistat $(60 \mathrm{mg})$ & USA & 5 & 0 & Yes \\
Benfluorex $(150 \mathrm{mg})$ & France & 2 & 0 & Yes \\
Rimonabant $(20 \mathrm{mg})$ & India & 1 & 0 & Yes \\
Orlistat $(120 \mathrm{mg})$ & Switzerland & 1 & 2 & Yes \\
Rhei rhubarb & China & 1 & 0 & Yes \\
Orlistat* $(120 \mathrm{mg})$ & India & 0 & 1 & Unknown \\
\hline
\end{tabular}

*Labelled manufacturer did not reply.

sibutramine in Germany was suspended in January 2010, and it was not approved for use in the USA.

\section{DISCUSSION}

\section{Provided information on the samples}

According to the Pharmaceutical Affairs Law (PAL) in Japan, advertising of unapproved medicines is prohibited, and customs should seize any shipment of prescription medicines when the amount exceeds more than a 1-month dose or any non-prescription medicines that exceed more than a 2-month dose. However, at least some of the samples in this study that exceeded the approved amount for shipment made it through the regulatory checks during shipping. ${ }^{38}$ Surprisingly, at least four of the shipping companies are conducting business in Japan. Contact information was not provided on many of the sites $(52.8 \%)$, which seemingly contradicts ASCT. ${ }^{36}$ According to our study, nearly $50 \%$ of the sites mentioned dosage administration, effects or side effects of the medicines, which are not permitted by the PAL in Japan. ${ }^{38}$ As found in many previous studies on e-medicines, approximately $50 \%$ of the samples did not contain a package insert. ${ }^{35-42}$ Moreover, several of the weight loss products may contain harmful or contraindicated ingredients. ${ }^{33} 39$ Similar to the findings of a recent study, none of the websites of our study required a prescription to purchase medicines. ${ }^{43} 44$

\section{Approval status of the products}

The majority of the study samples were sibutramine, which is a selective inhibitor of the central neuronal

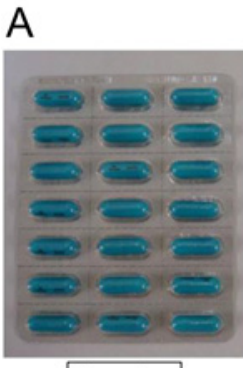

Genuine

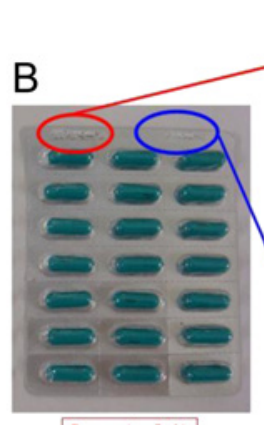

Counterfeit

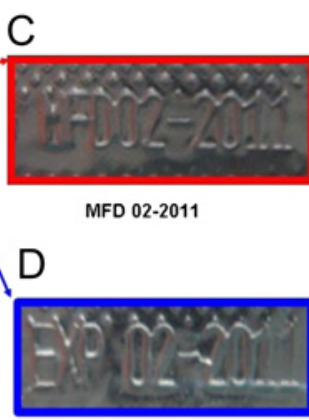

EXP 02-2011
Figure 2 Front of blister: (A) genuine sample, (B) counterfeit sample, (C) manufacturing date of counterfeit sample (MFD 02-2011), and (D) expiration date of counterfeit sample (EXP 02-2011). reuptake of serotonin and norepinephrine and reduces food intake and body weight. ${ }^{45}$ However, after conclusion of the safety review of sibutramine, the European Medicines Agency has suspended its marketing authorisation in the European Union (EU) ${ }^{46} \mathrm{~A}$ recently published study reported that generic Figurer (sibutramine $10 \mathrm{mg}$ ), even though it has not been reviewed by the responsible government (the USA, the exporting nation), is freely circulating via the internet, which is a serious concern for public health. ${ }^{35}$ According to the medicine regulations of Hong Kong, Figurer does not need manufacturing authorisation because the medicine is manufactured in a foreign country. The authorisation status of Alli (orlistat $60 \mathrm{mg}$ ) as a prescription medicine has been recommended to transition to a non-prescription medicine in the EU. ${ }^{47}$ In a questionnaire conducted by community pharmacists in Great Britain, orlistat is suspected to be misused by consumers, as stated in their responses. ${ }^{48}$ Similarly, marketing authorisation for Acomplia (rimonabant) has also been withdrawn in the EU in January 2009, and safety profiles of other antiobesity agents are generating controversy in different parts of the world. ${ }^{49-53}$ Even though all the anti-obesity agents sampled in this survey are unapproved in Japan, it is possible that anyone can procure these items without declaring the actual contents during shipping.

\section{Authenticity and quality of the samples}

As similarly shown in previous studies, we observed low rates of authenticity. ${ }^{54}$ Responses from only five (25\%) of
A

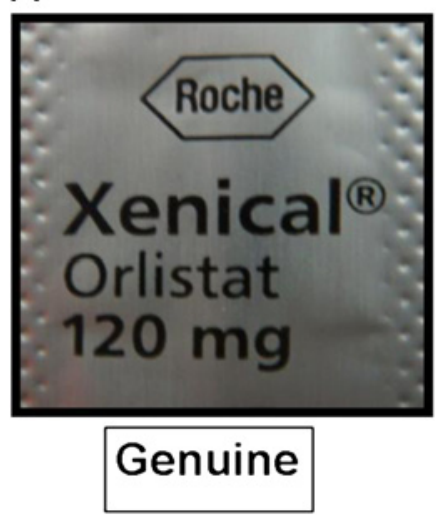

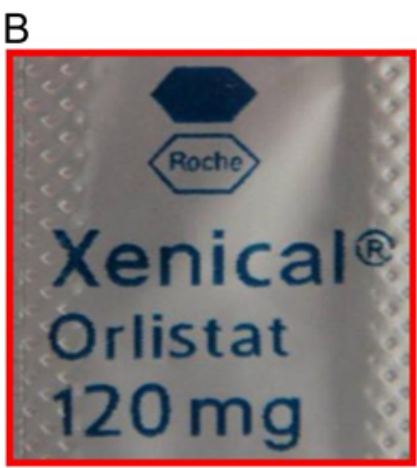

Counterfeit
Figure 3 Reverse side of blister: (A) logo of genuine sample and $(B)$ logo of counterfeit sample. 
the manufacturers for $14.6 \%$ of the samples were received. The counterfeit samples identified in this survey were confirmed by the manufacturer of the corresponding genuine products. Counterfeiting of antiobesity medicines, particularly orlistat, has been previously reported. ${ }^{5556}$ Based on the external characteristics of the counterfeits, these products most often differ in their printed information, design, colour, and so on from those of the genuine drugs. ${ }^{17} 57$ As shown in some other studies, the counterfeits detected in this survey did not contain any active ingredients. ${ }^{54} 58$ It is not clear why the manufacture of Zenigal, which failed the content analysis, did not respond to our authentication request. In such a case, it can be assumed that the manufacturer is already aware of the distribution of low-quality products in the pharmaceutical market. Several reports suggest that patients have sought medical treatment for life-threatening complications after the consumption of fake or substandard medicines purchased online. ${ }^{59}$ When products are purchased through the internet and the sites are not sufficiently regulated, customers are left to accept the consequences.

According to the PAL, a person violating pharmaceutical regulation may be sentenced to an imprisonment of up to 3 years or imposed a penalty of up to JP $¥ 3$ million or both. ${ }^{60}$ In case of such violation by a company, the penalty may be increased to a maximum JP¥ 100 million. ${ }^{60}$ Nevertheless, PAL has only jurisdiction to regulate domestic traders and has no hold on foreign online traders. Strengthening international collaboration along with public-private partnership initiatives may facilitate stemming out illegal internet trading hosted from outside national boundaries. ${ }^{19} 6162$

One of the limitations of the study might be small sample size, which may restrict study findings to Japan. The sampling scheme may also limit our findings from generalisation to all internet sites. However, the sampling scheme was purposefully designed to investigate suspicious online medicine sites. Our study was not designed comprehensively to explore information during shipment of medicinal products, especially at Japanese custom check. Further evaluation with a representative sample may provide more information on the extent of the problem. Low response rate of authenticity investigation may also be considered as a limiting factor. However, better communication and cooperation among authentic manufacturers and medicine regulatory authorities may increase response rate and generate more information to counteract against counterfeits.

\section{CONCLUSIONS}

It is evident from this study that counterfeit, unapproved and suspended anti-obesity medicines, are circulating via the internet. Because of gaps and the insufficient monitoring system of imports for personal use in the rapidly growing e-commerce environment, these medicines can easily enter into the distribution channels for pharmaceuticals and may pose health hazards for consumers. Time has come to address such gaps of crossborder pharmaceutical e-commerce and regulate the same through international cooperation and publicprivate partnerships. Obviously, first and foremost step should be at country levels to make necessary amendments of existing regulation focusing online pharmaceutical transactions. Furthermore, there might be an urgent need at international level to formulate common regulation and agreements focusing issues of pharmaceutical e-commerce.

Acknowledgements We gratefully acknowledge the cooperation received from the staff of Ministry of Health and Labour Welfare.

Contributors MHK, TT, YN and KK participated in the conception and design of the study. TT, YN and KK participated in sampling activities and analysis of the samples. MHK, TT, YN, NY, HT and KK participated in data analysis and interpretation of results. MHK wrote the first draft of the manuscript. All authors contributed in the critical review of the draft manuscript, editing and finally approved its submitted version.

Funding This study was supported by Research Grants from the Ministry of Health and Labour Welfare, Japan.

\section{Competing interests None.}

Provenance and peer review Not commissioned; externally peer reviewed

Data sharing statement No additional data are available.

\section{REFERENCES}

1. Madden M. America's Online Pursuits: the Changing Picture of Who's Online and What They Do. Washington, DC: Pew Internet, 2003.

2. Atkinson NL, Saperstein SL, Pleis J. Using the internet for healthrelated activities: findings from a national probability sample. $J$ Med Internet Res 2009;11:e4.

3. Askola K, Atsushi T, Huotari ML. Cultural differences in the health information environments and practices between finnish and Japanese university students. Inform Res 2010;15:451.

4. Takahashi Y, Ohura T, Ishizaki T, et al. Internet use for health-related information via personal computers and cell phones in Japan: a crosssectional population-based survey. J Med Internet Res 2011;13:e110

5. Araki R, Okumura J, Akazawa $M$, et al. A survey on the awareness of consumers on their personal import of medicines from public health view point. Jpn J Soc Pharm 2010;28:134-5.

6. WHO. Medicines: Counterfeit Medicines. Geneva: World Health Organization, 2010; [Fact sheet No. 275]. http://www.who.int/ mediacentre/factsheets/fs275/en/index.html (accessed 8 Mar 2010).

7. WHO. Counterfeit Drugs: Guidelines for the Development of Measures to Combat Counterfeit Drugs. Geneva, Switzerland: Department of Essential Drugs and Other Medicines, World Health Organization, 1999. Report No.: (WHO/EDM/QSM/99.1).

8. WHO. General Information on Counterfeit Medicines. Geneva: World Health Organization, 2009. http://www.who.int/medicines/services/ counterfeit/overview/en/ (accessed 27 May 2009).

9. IMPACT. Principles and Elements for National Legislation against Counterfeit Medical Products: Text Endorsed by IMPACT General Meeting. Lisbon: International Medical Products Anti-Counterfeiting Taskforce, 2007.

10. WHO. What Are Substandard Drugs? Geneva: World Health Organization, 2009. http://www.who.int/medicines/services/ counterfeit/faqs/06/en/index.html (accessed 15 Jul 2009).

11. Surendran A. World agencies try to stem flood of fake drugs. Nat Med 2004;10:111.

12. Kelesidis T, Kelesidis I, Rafailidis PI, et al. Counterfeit or substandard antimicrobial drugs: a review of the scientific evidence. J Antimicrob Chemother 2007:60:214-36.

13. Kaur H, Goodman C, Thompson E, et al. A nationwide survey of the quality of antimalarials in retail outlets in Tanzania. PLoS One 2008;3 e3403.

14. Onwujekwe $\mathrm{O}$, Kaur $\mathrm{H}$, Dike $\mathrm{N}$, et al. Quality of anti-malarial drugs provided by public and private healthcare providers in south-east Nigeria. Malar J 2009;8:22.

15. Newton PN, Green MD, Fernández FM, et al. Counterfeit antiinfective drugs. Lancet Infect Dis 2006;6:602-13.

16. Khan AY, Ghilzai NM. Counterfeit and substandard quality of drugs: the need for an effective and stringent regulatory control in 
India and other developing countries. Indian J Pharmacol 2007;39:206-7.

17. Newton PN, Fernández FM, Plançon A, et al. A collaborative epidemiological investigation into the criminal fake artesunate trade in South East Asia. PLoS Med 2008;5:e32.

18. Liang BA, Mackey T. Searching for safety: addressing search engine, website, and provider accountability for illicit online drug sales. Am J Law Med 2009;35:125-84

19. Mackey TK, Liang BA. The global counterfeit drug trade: patient safety and public health risks. J Pharm Sci 2011;100:4571-9.

20. Letkiewicz S, Górski A. The potential dual use of online pharmacies. Sci Eng Ethics 2010;16:59-75.

21. WHO. 2008-2013 Action Plan for the Global Strategy for the Prevention and Control of Noncommunicable Diseases. Geneva: World Health Organization, 2008.

22. James WPT. The epidemiology of obesity: the size of the problem. $J$ Intern Med 2008;263:336-52.

23. Moreno LA, Pigeot I, Ahrens W, et al. Prevalence of Overweight and Obesity in Japan. Epidemiology of Obesity in Children and Adolescents. New York: Springer, 2011:153-62.

24. Snow V, Barry $\mathrm{P}$, Fitterman N, et al. Pharmacologic and surgical management of obesity in primary care: a clinical practice guideline from the American College of Physicians. Ann Intern Med 2005;142:525-31.

25. Lowes R, Waknine Y. FDA Announces Sibutramine Has Been Withdrawn From the Market. Medscape Education [serial on the Internet]. 2010. http://www.medscape.org/viewarticle/730515 (accessed 25 Oct 2011).

26. FDA. FDA Drug Safety Communication: FDA Recommends Against the Continued Use of Meridia (sibutramine). Rockville, MD, 2010 http://www.fda.gov/Drugs/DrugSafety/ucm228746.htm (accessed 25 Oct 2011).

27. MHLW. Authorization Status of Drugs in Japan. Tokyo: Ministry of Health and Labour Welfare, 2011. http://www.info.pmda.go.jp/ psearch/html/menu_tenpu_base.html (accessed 30 Jun 2011)

28. Tsuji K, Tsutani K. Personal imports of drugs to Japan in 2005 - an analysis of import certificates. J Clin Pharm Ther 2008;33:545-52.

29. Eisai. Withdrawal of Approval for Manufacture and Sale of $A$ Therapeutic Agent for Obesity in Japan KES524. Tokyo: Eisai Co., Ltd., 2010. http:// www.eisai.co.jp/news/news201057.html (accessed 7 Mar 2010).

30. deKieffer DE. The internet and the globalization of counterfeit drugs. $J$ Pharm Pract 2006;19:171-7.

31. Jackson G. Faking it: the dangers of counterfeit medicine on the internet. Int J Clin Pract 2009;63:181.

32. Bogenschutz MP. Drugs on the internet. Am J Psychiatry 2001;158:2094-5.

33. MHLW. Warning on Health Hazard Due to Counterfeit Medicines. Tokyo: Ministry of Health and Labour Welfare, 2011. http://www. mhlw.go.jp/stf/houdou/2r9852000001agwf-att/2r9852000001ah0e. pdf (accessed 4 Oct 2011).

34. Pfizer. Result of Joint Investigation Done by Four Manufacturers: Approximately $60 \%$ of ED Treatment Medicines are Counterfeits on the Internet. Tokyo, 2009. http://www.pfizer.co.jp/pfizer/company/ press/2009/2009_12_02.html

35. Kimura K, Honma T, Tanimoto T, et al. Public health implication of personal import of medicines through internet brokers (2): buying anti-obsity agents on-line. J Health Care \& Society 2011; 21:55-67.

36. METI. Specified Commercial Transaction Law to Regulate Mail-order Business. Tokyo, Japan: Ministry of Economy, Trade and Industry, 1976.

37. Aka E, Legris C, Tanimoto $\mathrm{T}$, et al. Counterfeit medicine detection by authenticity investigation: a pilot study in the street market of Côte d'Ivoire. Jpn J Soc Pharm 2005;24:7-16.

38. MHLW. Pharmaceutical Affairs Law, Japan. Tokyo: Ministry of Health and Labour Welfare, 2011. http://www.houko.com/00/01/S35/145. HTM (accessed 4 Oct 2011).

39. Nazeri A, Massumi A, Wilson JM, et al. Arrhythmogenicity of weightloss supplements marketed on the Internet. Heart Rhythm 2009;6:658-62.

40. Veronin MA, Youan BB. Magic bullet gone astray: medications and the internet. Science 2004;305:481.

41. Martin-Facklam M, Kostrzewa M, Schubert F, et al. Quality markers of drug information on the internet: an evaluation of sites about St. John's Wort. Am J Med 2002;113:740-5.

42. Westenberger BJ, Ellison CD, Fussner AS, et al. Quality assessment of internet pharmaceutical products using traditional and nontraditional analytical techniques. Int J Pharm 2005;306:56-70.
43. Orizio G, Rubinelli S, Schulz PJ, et al. "Save $30 \%$ if you buy today". Online pharmacies and the enhancement of peripheral thinking in consumers. Pharmacoepidemiol Drug Saf 2010;19:970-6.

44. Orizio G, Merla A, Schulz PJ, et al. Quality of online pharmacies and websites selling prescription drugs: a systematic review. J Med Internet Res 2011;13:e74.

45. Tziomalos K, Krassas GE, Tzotzas T. The use of sibutramine in the management of obesity and related disorders: an update. Vasc Health Risk Manag 2009;5:441-52.

46. EMEA. European Medicines Agency Recommends Suspension of Marketing Authorisation for Sibutramine. London: European Medicines Agency, 2010. http://www.ema.europa.eu/ema/index.jsp? curl=pages/news_and_events/news/2010/01/news_detail_000985. jsp\&murl=menus/news_and_events/news_and_events. jsp\&mid $=$ WCOb01ac058004d5c1 (accessed 9 Jun 2011).

47. EMEA. European Medicines Agency Recommends First Switch From Prescription Only to Non-Prescription for a Centrally Authorised Medicine. 2008. Doc. Ref. EMEA/CHMP/493770/2008. http://www.ema europa.eu/ema/index.jsp?curl=pages/news_and_events/news/2009/11/ news detail 000256.jsp\&murl=menus/news and events/ news_and_events.jsp\&mid=WC0b01ac058004d5c1\&jsenabled=true (accessed 24 Jun 2011).

48. Weidmann A, Cunningham S, Gray G, et al. Over-the-counter orlistat early experiences, views and attitudes of community pharmacists in Great Britain. Int J Clin Pharm 2011;33:1-7.

49. Alsheikh-Ali AA, Karas RH. Safety of lovastatin/extended release niacin compared with lovastatin alone, atorvastatin alone, pravastatin alone, and simvastatin alone (from the United States Food and Drug Administration adverse event reporting system). Am J Cardiol 2007;99:379-81.

50. Calza L. Long-term use of rosuvastatin: a critical risk benefit appraisa and comparison with other antihyperlipidemics. Drug Healthc Patient Saf 2009;1:25-33.

51. Perrio MJ, Wilton LV, Shakir SA. The safety profiles of orlistat and sibutramine: results of prescription-event monitoring studies in England. Obesity (Silver Spring) 2007;15:2712-22.

52. EMEA. European Medicines Agency Recommends Withdrawal of Benfluorex from the Market in European Union. London: European Medicines Agency, 2009. http://www.ema.europa.eu/ema/index.jsp? curl=pages/news_and_events/news/2010/01/news_detail_000977. jsp\&murl=menus/news_and_events/news_and_events.jsp\&mid $=$ WC0b01ac058004d5c1\&jsenabled=true (accessed 9 Jun 2011)

53. EMEA. Public Statement on Acomplia: Withdrawal of the Marketing Authorisation in the European Union. London: European Medicines Agency, 2009. http://www.ema.europa.eu/ema/index.jsp? curl=pages/news_and_events/news/2009/11/news_detail_000126. jsp\&murl $=$ menus/news and events/news and events. jsp\&mid=WC0b01ac058004d5c1 (accessed 9 Jun 2011)

54. Khan M, Okumura J, Sovannarith T, et al. Counterfeit medicines in Cambodia-Possible Causes. Pharm Res 2011;28:484-9.

55. FDA Warns Consumers about Counterfeit Alli [database on the Internet]. U.S. Food and Drug Administration, 2010. http://www.fda. gov/NewsEvents/Newsroom/PressAnnouncements/ucm197857.htm (accessed 3 Oct 2011)

56. UPDATED Public Health Alert: Counterfeit Alli Containing Sibutramine [database on the Internet]. U.S. Food and Drug Administration, 2010. http://www.fda.gov/Drugs/DrugSafety/ PostmarketDrugSafetylnformationforPatientsandProviders/ ucm 198519.htm (accessed 3 Oct 2011).

57. Dondorp AM, Newton PN, Mayxay M, et al. Fake antimalarials in Southeast Asia are a major impediment to malaria control: multinational cross-sectional survey on the prevalence of fake antimalarials. Trop Med Int Health 2004;9:1241-6.

58. Khan $\mathrm{MH}$, Okumura J, Sovannarith $\mathrm{T}$, et al. Prevalence of counterfeit anti-helminthic medicines: a cross-sectional survey in Cambodia. Trop Med Int Health 2010;15:639-44.

59. Lineberry TW, Bostwick JM. Taking the physician out of "physician shopping": a case series of clinical problems associated with internet purchases of medication. Mayo Clin Proc 2004;79:1031-4.

60. MHLW. Pharmaceutical Affairs Law, Japan. Tokyo: Ministry of Health and Labour Welfare, 1961. http://www.houko.com/00/01/S35/145. HTM (accessed 4 Oct 2011).

61. Mackey TK, Liang BA. Promoting online drug safety: using publicprivate partnerships to deter illicit online drug sales. J Commer Biotechnol 2011:17:266-71.

62. Cockburn R, Newton PN, Agyarko EK, et al. The global threat of counterfeit drugs: why industry and governments must communicate the dangers. PLoS Med 2005;2:e100. 


\section{Correction}

Khan MH, Tanimoto T, Nakanishi Y, et al. Public health concerns for anti-obesity medicines imported for personal use through the internet: a cross-sectional study. BMJ Open 2012;2: e000854. The captions for figures $1 \mathrm{C}$ and 1D should be "Counterfeit Zenigal (orlistat $120 \mathrm{mg}$ )" and "Counterfeit Xenical (orlistat 120mg)-2" respectively. The authors apologise for this error.

BMJ Open 2012;2:e000854corr1. doi:10.1136/bmjopen-2012-000854corr1 